\title{
Study on the Performance of Decorative Colors and Materials on Ceramics
}

\author{
Jian Zheng ${ }^{1, \text { a }}$ \\ ${ }^{1}$ Panzhihua University, Panzhihua, Sicuan, 617000 \\ ${ }^{a}$ email
}

Keywords: Decorative Colors; Materials; Ceramic Performances

\begin{abstract}
The main topic of reincarnation colors and different materials used in the performance of ceramic appearance, were ceramic color performance with a special technique, combining ancient beauty and modern beauty, this study as a starting point.
\end{abstract}

\section{Introduction}

Ceramic is an important cultural heritage of mankind is to prove the existence of a history, but also still a major form remain in people's life and production, occupies an important position. Our ceramic culture has been regarded as an important aspect of Chinese civilization achievements reflect the spirit and charisma. With the era of progress and a lot of social elements into new ceramics, the use of color elements of the original color to make the performance of different colors and decorative ceramic material leads to the performance characteristics of the times are not the same. Pottery from the Stone Age to the Song Dynasty blue and white, even to the Ming dynasty colorful, these trends reflect the characteristics of an era of change in the form of characteristic changes, the presentation is characterized by a trend of the times change.

\section{A Decorative Color in the Ceramic Era Characterized Style}

Every era has produced a new thing, the overall presentation of the trend is the changing of the times. In this ceramic decoration color seen things most everyday performance is the most direct, is reflected in the change of an era, reflecting the people's living conditions, such as at the time of the Tang Dynasty, Tang Dynasty more common, is the most prosperous Tang Dynasty culture expression. Han pottery ceramics ancient cultural treasures, the full name of the Tang Dynasty three glazed pottery of the Tang Dynasty is prevalent in a low-temperature glazed pottery, glazed yellow, green, white, brown, blue, black and other colors, and yellow, green, white color-based, so people used to call "Tang." Because the earliest pottery, most unearthed in Luoyang, also "Luoyang Tang Dynasty," said. For example FIG. First, the "three-color Ladies'

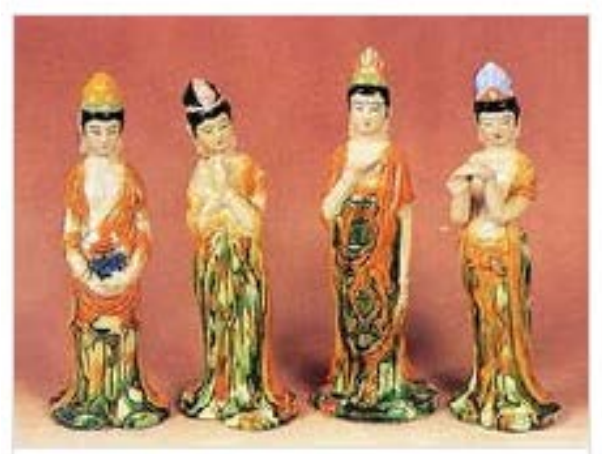

Figure. 1 Three-color Ladies

Ceramic color performance of each period is different, and the technology of that period is associated, is an era of ideology and culture, reflecting subsistence. For example, in ancient times, the ceramic material is to use a simple baked material is relatively simple, the firing is the same way, forming a deep and pure beauty of color. Only simple lines outline, but it can be an art exhibit unique charm, people feel refreshing. 
With the progress of the times, in a time of the Song Dynasty porcelain, mostly in blue tone is carried out corresponding to the sculpture. Tang and Song Dynasty blue and white porcelain, also known as white, blue and white porcelain, referred to as the blue and white, with high artistic value. Tang and Song porcelain is one of the domestic market is now the most precious antique collections, is one of the main varieties of Chinese porcelain belonging to the genus underglaze porcelain. Strong sense of blue and white coloring, and the firing rate, color stability characteristics of the original blue and white porcelain in the Tang and Song is emerging, mature in the Yuan Dynasty blue and white porcelain Jingdezhen appeared Hutian. Ming Dynasty blue and white porcelain became the mainstream. Kangxi developed to its peak time. Ming and Qing Dynasties, also fired in a colorful blue and white, peacock green blue, green glazed blue and white beans, red blue and white color, yellow to blue, Columbia blue and white enamel and other derivatives.

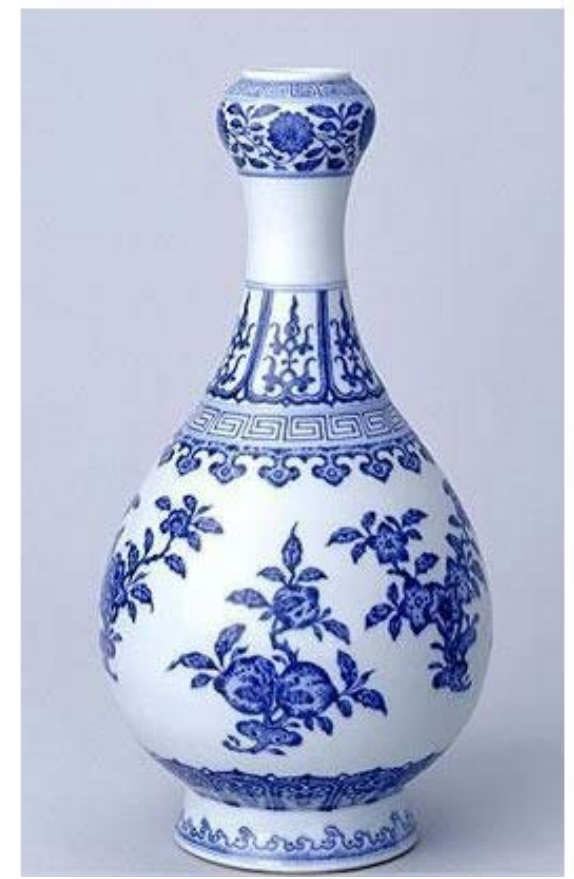

Figure. 2 Blue and white porcelain

A good ceramic art, careful design is inseparable from ceramics craftsmen, how to make decorative colors and materials appropriate integration in ceramics, showing the charm of ceramic art. Different ceramics decorative colors, a wide range of materials, make this ceramic art emerged with the charm of art are not the same, the use of color to fit the characteristics of the times, with the change of life situation and adapt. Ceramic use of color along with the strengthening of contemporary show another color different from the traditional beauty of harmony. In recent years, the development trend of ceramic color sense is performance-based, it attaches to points, lines, faces the main technique of expression, the use of a variety of brush strokes full of freshness, to be shown things highlighted with color, to achieve a sense of color strong, so that the viewer does not feel the same as the color of the United States.

The main test of the production process technology, requires constant element of integration. The importance of color in the color of the area corresponding to the position, as well as between colors, show producers want to show out of the artistic ideas, reflect personal feelings. This is inseparable from the perception of life.

Color ceramic surface and can be integrated into a number of human performance are not the same way, the way the presentation of artistic expression are not the same, into the color of the elements, so the effect of the whole ceramic art becomes more different . For example the following figure, two bowls, as solid colors and coloring, showing different artistic ornamental value. 


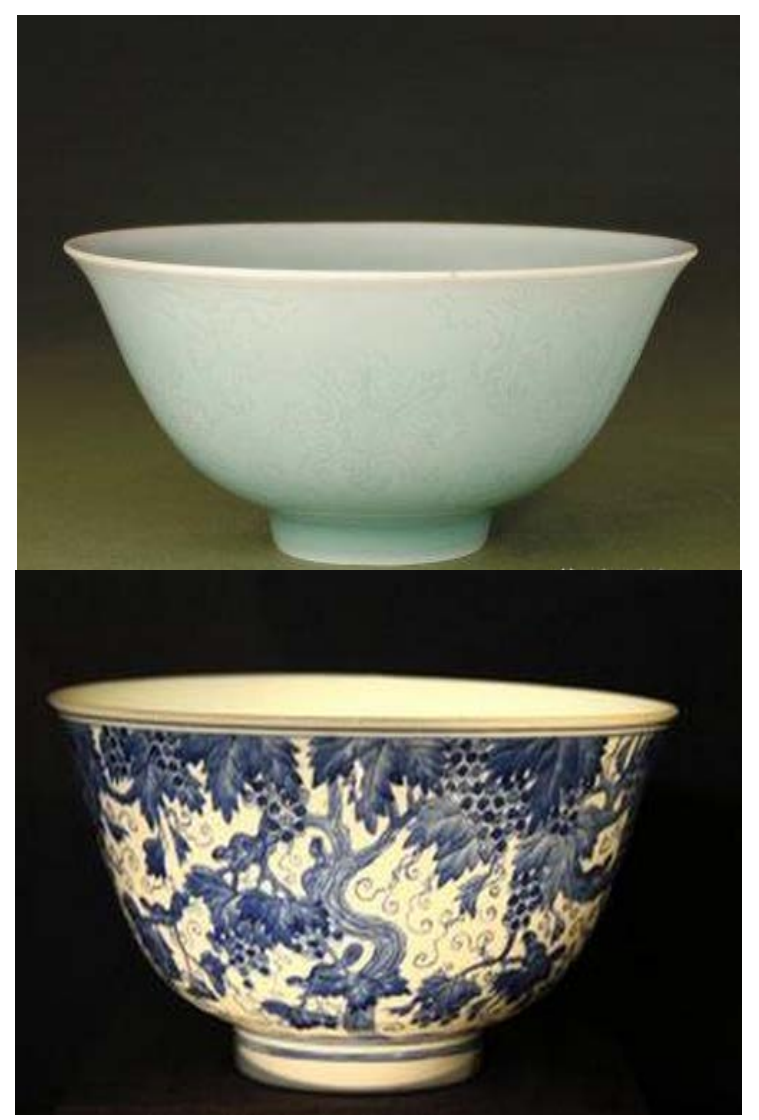

Each local soil is not the same, resulting in ceramic firing is not the same way, the use of color colored different. Colors in ceramic applications, taking into account the actual texture of ceramic materials is generally good soil out of the firing ceramics, transparent, can make an impact, people see different variations of the above cultures. Jingdezhen porcelain such as sericite, it has the characteristics of white in the Fan Qing; ceramic feldspathic porcelain and high whiteness porcelain ceramic industry is a commonly employed. For this texture, we need to use different elements for decoration.

Ceramics decorative colors and the local folk can not do without, such as red is a symbol of Chinese festive, great events in the past, when using decorative color is red, when married with a large red, New Year's time, you need to paste red couplet. Different countries, different regions, and different understanding of color. For example, white is unfortunate country representatives, while in Western countries, but it is a symbol of purity, get married, with most of them are white. Therefore, the ceramic decoration color when you need to know the local customs. According to the relevant understanding psychologist, change the color and mood of people and living environment can not be separated, for example, when setting up traffic lights, to take into account human visual ability to accept, and the use of these three red yellow and green colors. Ceramic colors and is closely related to our living environment, combined with the local folk design is a new kind of idea generation.

\section{The Decoration Color in Ceramic Art in the Course of Development}

China's ceramic decoration in the use of color has a long history, dating back to the Neolithic pottery pottery color application to application, from the application of a single color elements to take advantage of a variety of color elements, and it is inseparable from the development of the times, They are closely linked. Color Neolithic era mainly white, basic colors black, red, gray and so on. This can be verified from the Dunhuang murals and painted sculptures. Color compared to the Dunhuang Grottoes inside the Ming and Qing Dynasties, it is relatively simple. But it contains a wealth of cultural connotations, it is possible to some extent, the expression of the social scene for subsequent studies show the color is not the same as the above.

Tang and Song time as technology advances, the use of color elements highlight techniques, pottery is one of the most important manifestations of this period practices. Color is a magnificent 
performance, is characteristic of an era display. With the progress of history, decorative colors in ceramic applications gradually become a characteristic, become unique artistic style of representation, as part of China's cultural treasure house of splendid democracy. There are five basic color color, Chinese ceramics decorative colors exceptionally unique feeling, can appreciate the collective emotions of a nation express in color ceramics, such as Westerners prefer color decoration Chinese blue and white porcelain on top the emphasis is on a harmonious tone, reflecting a romantic charm, gives a simple, simple, twist inquiry feel fully reflected Chinese flavor.

\section{The Integration of Contemporary Chinese Ceramic Decoration Color Developing New Elements}

Art and modern people's lives are closely related to ceramics, ceramic close to people's lives, such as cups, bowls and these people are common ceramic art. Compared to other art, ceramic art to better reflect the state of people's lives, the content of decorative features, color, form of performance art practices, they are of an era.

With economic development, people's living standards improve, the pursuit of only the enjoyment of material life, as well as the spirit of enjoyment. Life supplies requirements increase, the need to change people's present form of artistic expression of diverse techniques. Ceramic decorative performance practices in the original color of the above improvements, the promotion of more vivid color, fit people's lives aesthetic ideas.

Color matching is not simple, especially in the beginning of the liberation of the new China, the original color of the control of the old society open to, people can be cited for more color change is no longer a dedicated official colors. Variety of color elements can exhibit a certain degree of cultural diversity.

\section{The Meaning of Decorative Colors and Materials Utilized in the Ceramic}

Now decorative elements than before and up to varied ceramic is environmentally friendly elements into modern decor in the past, it is possible to some extent, to avoid the use of chemical materials from these subtle dishes daily necessities, to decoration lighting, it is ceramic, which greatly promoted the development of ceramic industry.

Development of new technology, so that more and more exquisite ceramics manufactures, which are now the art of transformation model, a paradigm shift is now an important factor in the development of the arts. Is inseparable from the development of ceramic technology advances, this is an important factor in the transition mode characteristics of the times.

Soil texture made of ceramic and has a vital link, the soil in some places can not be fired ceramics, but with the development of technology, it is possible to promote the development of ceramic technology. To solve the technical problem above, a ceramic batch production, it is significant progress, a lot of production, can promote ceramic applications.

Ceramics is unique to our industry chain, it is possible to some extent, stimulating the growth of the national economy, promote the rapid growth of the ceramic production base of the economy. Jingdezhen For example, in this place, when the original Ming and Qing kiln important origin, now it is important to place the production of ceramics, in some places to buy ceramics in Jingdezhen is specifically designed to look for the brand. Would like to produce the corresponding brand effect, can increase the associated economic benefits.

Ceramics production in our country can be said to be a long history, from ancient times ceramics began to be fired up, that time can not become ceramic pottery, simply placing something artifacts, know the beginning of the Tang Dynasty, the ceramic only in true famous. Promotion of large areas of ceramic, capable of promoting the people's concept of modern ceramic art of the above changes to some extent.

Decoration color theory is the color of specialized research to guide people color art practice, relations which mainly use the color coordination, the impact on the art form of things, to promote the development of ceramic related industries. 


\section{Conclusion}

The above decorative ceramic colors and materials in use can to a certain extent, promote the visibility of ceramics. Ceramic is our art treasures, other materials can not replace the art. Ceramic technology is changing the original pure manual mode of production can not meet the needs of the community, a large-scale manufacturer of machines now used to meet delivery ceramics, decorative bold use of color, it is possible to some extent to promote the ceramic artistic effect can be beneficial in a wider use of ceramic spheres of life. Now ceramic products decorative ceramic furnishings, ceramic wall ornaments, ceramics furniture, ceramics and other means, I believe that progress with the times, the ceramic will be more integrated into people's daily life in the past.

\section{References}

[1] Wu Tianlin. On the Decorative Colors Chinese Ceramic Art [J]. Chinese Ceramics, 2007, 43 (4): 66-67.

[2] Feng Shaohua. Decorative Ceramic Tint [J]. Jingdezhen Ceramic, 2001, 11 (4): 25-28.

[3] Yu Kangtai, Liu Ruping. Situation and Development Trend of Building Ceramics Decoration Techniques [C]. Chinese Ceramic Society Ceramic Branch 2006 Annual Conference Papers Album 2006: 304-308.

[4] Tian Sisi. Ceramic Art Design Color Emotions Discussion [J]. Modern Decor: Theory, 2014 (1).

[5] Wang Lili. Ceramic Decoration in the Use of Color [J]. Science and Technology Information, 2008 (30): 229-229.

[6] Jiang Wei. Chinese Ceramic Art Decorative Colors, [J]. East China Science and Technology: Academic Edition, 2013 (9): 408-408.

[7] Zhang Chaohui, Liu Fang. The Study Aesthetic Characteristics Jingdezhen Ceramic Jewelry [J]. Nanjing Art Institute: Art and Design Edition, 2009 (6): 97-100.

[8] Yu Kangtai, Liu Ruping. Situation and Development Trend of Building Ceramics Decoration Techniques [J]. Ceramic, 2006, 27 (3): 304-308. 